\title{
Limb Differences in the Therapeutic Effects of Complex Decongestive Therapy on Edema, Quality of Life, and Satisfaction in Lymphedema Patients
}

\author{
Sujin Noh, $\mathrm{MD}^{1}$, Ji Hye Hwang, MD, $\mathrm{PhD}^{1}$, Tae Hee Yoon, $\mathrm{MD}^{1}$, \\ Hyun Ju Chang, BA ${ }^{1}$, In Ho Chu, MS ${ }^{1}$, Jung Hyun Kim, MS $^{2}$
}

${ }^{1}$ Department of Physical and Rehabilitation Medicine, Samsung Medical Center, Sungkyunkwan University
School of Medicine, Seoul; ${ }^{2}$ Center for Clinical Medicine, Samsung Medical Center, Seoul, Korea

Objective To investigate the changing patterns of edema, quality of life (QOL), and patient-satisfaction after complex decongestive therapy (CDT) in three trajectories: arm lymphedema (AL), secondary leg lymphedema (LL) and primary leg lymphedema (PL).

Methods Candidates for AL ( $\mathrm{n}=35)$, LL $(\mathrm{n}=35)$ and PL $(\mathrm{n}=14)$ were identified from prospective databases. The patients were treated with CDT for 2 weeks, and lymphedema volume was measured before and immediately following the therapy. Patients then self-administered home therapy for 3 months and presented for a follow-up visit. The Korean version of Short Form-36 (SF-36) was used to assess QOL, and we administered a study-specific satisfaction survey.

Results There was no significant difference in the volume reductions between the 3 groups. There were no significant differences in all of the measures between PL and LL. Overall initial QOL was significantly lower in patients with LL than in patients with AL. SF-36 scores post-CDT did not differ significantly between AL and LL. Clinically significant differences were noted between AL and LL in the mean values of the satisfaction survey. Conclusion AL, LL, and PL may have different longitudinal courses. We suggest that lower extremity lymphedema patients present more favorable outcomes after CDT with respect to QOL and satisfaction than upper extremity lymphedema patients. Clinicians should approach patients with different therapeutic considerations specific to each type or region of lymphedema before using CDT in clinical practice.

Keywords Lymphedema, Therapy, Quality of life, Personal satisfaction licenses/by-nc/4.0) which permits unrestricted noncommercial use, distribution, and reproduction in any medium, provided the original work is properly cited. Copyright $\odot 2015$ by Korean Academy of Rehabilitation Medicine 


\section{INTRODUCTION}

Lymphedema is a chronic disease that is associated with decreased physical, psychological, and social wellbeing as well as quality of life (QOL) [1-3]. The perception of the state of health and QOL of patients are widely recognized as important issues, and the treatment goals of patients with lymphedema include preservation of QOL [4-6].

Unfortunately, many of the treatment strategies used have not been proven to be successful in preventing the occurrence of lymphedema. Although secondary treatment is the best strategy for lymphedema, there is no definite treatment guideline [7-10]. However, complex decongestive therapy (CDT) is currently recognized as a standard lymphedema treatment, focusing on reduction in limb volume and maintenance of healthy skin $[9,11,12]$. CDT results in minimal loss of function and QOL $[1,8,13,14]$. Interest has been stimulated by research into the effects of CDT on volume reduction and QOL [2,4,5,15-17].

In our experience, there are no distinct differences in the effectiveness of CDT in treating the two recognized types of lymphedema (primary and secondary). However, we have found that the clinical effectiveness of and satisfaction with CDT do not appear to be the same in patients with arm lymphedema (AL) and leg lymphedema (LL). Few studies have specifically compared the influence of CDT on QOL between limb groups and lymphedema types $[10,15,17]$, and well-designed studies are lacking. Moreover, there is little information about the reported efficacy of and satisfaction with CDT. In the clinical setting, the consequences of low treatment satisfaction with clinical treatment are a particular concern in patients with functional limitations. Therefore, understanding treatment effectiveness and the patient's view of CDT may help in the assessment of lymphedema patients.

The specific objective of this prospective study was to characterize the changing patterns of edema, QOL, and patient-satisfaction after CDT according to limb groups as well as lymphedema types.

\section{MATERIALS AND METHODS}

\section{Subjects}

This prospective study included patients with minimal to moderate, unilateral AL or LL between September 1, 2011 and August 31, 2012 attending an outpatient clinic at Samsung Medical Center. Approval for the study was obtained from the Ethics Committee, and written consent was received from all patients.

A physician diagnosed lymphedema on a clinical basis in patients who had developed a swollen limb. In patients with primary lymphedema, lymphatic scintigraphy was used to confirm the diagnosis. The inclusion criteria for this study were 1) unilateral lymphedema and 2) minimal to moderate lymphedema. The severity of lymphedema was determined using the International Society of Lymphology (ISL) criteria, which are based on volume differences and assessed as minimal ( $<20 \%$ increase), moderate $(20 \%-40 \%$ increase), or severe $(>40 \%$ increase) differences [7].

Because a normal contralateral limb was required to predict the unaffected limb size, patients with bilateral lymphedema were excluded. Patients with untreated or unstable medical conditions, current vascular disease, or a history of attempted lymphedema reduction in the affected limb, were also excluded.

\section{Complex decongestive therapy}

All patients received $10 \mathrm{CDT}$ sessions of 90 minutes each, which included all of following components: manual lymph drainage massage, multilayered inelastic compression bandaging, and meticulous skin care $[6,7,11,18]$. This intervention continued for 2 weeks ( 5 working days per week). For the first 60 minutes of each 90 -minute session, manual lymphatic drainage was performed by certified therapists, followed by wrapping of the limb with short-stretch compression bandages and use of a sequential pneumatic pump for 30 minutes. During the 2 weeks of CDT, the patients were educated regarding the proper bandaging technique and medical remedial exercise to promote lymph drainage, maintenance of ideal body weight, and essentials of skin care during a comprehensive seminar. The patients were asked to massage daily, perform exercises, and care for their skin for the duration of the trial. Patients were fitted for compression garments (e.g., a stocking) after the initial 2 weeks of CDT. Clinical characteristics were obtained from a chart review on the day of CDT initiation. 


\section{Participants' enrollment and allocation}

After consent, 150 patients of the eligible 169 patients with lymphedema underwent the pre-CDT volume check and independently responded to the QOL survey. Of these participants, 84 completed the 12 -week visit and were included in the analysis. Of the 150 lymphedema patients, 15 did not fully attend the CDT program, 16 did not complete the post-treatment assessment, and 24 did not complete the 12-week assessment. Eleven patients were excluded because of an unstable medical condition or vascular disease during the follow-up period: 8 patients developed cellulitis, and 3 patients experienced recurrent tumors during the study (Fig. 1).

\section{Outcome measurements \\ Limb volume measurements}

Limb lymphedema volumes were measured using the electronic volumeter device (Perometer; Pero-System, Wuppertal, Germany), which is an optoelectronic instrument for measuring limb volume and circumferences $[19,20]$. The measurements were obtained twice at each exam by another examiner, and these automatically calculated values $(\mathrm{mL})$ were then averaged. Reproducibility of the Perometer has been confirmed by our institutions and by others $[11,18-20]$.

The volume measurements were carried out 3 times in both groups: pre-CDT (day of treatment initiation), post-

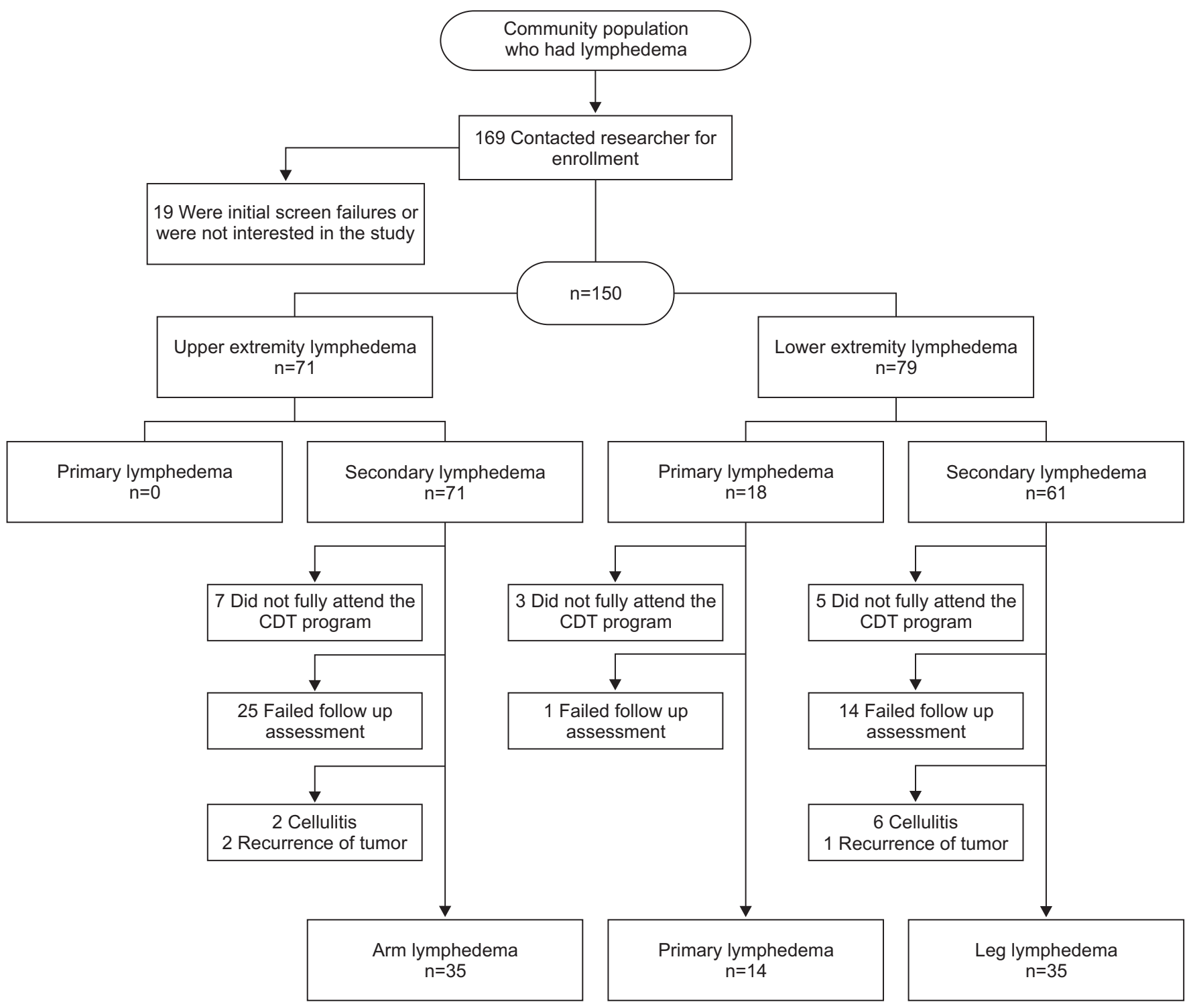

Fig. 1. Recruitment and retention of patients with lymphedema. CDT, complex decongestive therapy. 
CDT (2 weeks after treatment initiation), and 12 weeks after the end of the treatments ( 14 weeks after treatment initiation). Patients who did not undergo all 3 measurements were excluded from analysis.

The severity of swelling was determined by subtracting the volume of the patient's unaffected limb from that of the affected edematous limb. The therapeutic response of CDT was quantified as the change in the percentage of excess limb volume (PCEV), which is the most common indicator of edema volume and calculated using the following formula $[5,15,18,21,22]$ :

$$
\begin{aligned}
\operatorname{PCEV~}(\%)= & {[\text { (volume of affected limb }- \text { volume of }} \\
& \text { unaffected limb) } / \text { volume of unaffected } \\
& \text { limb }] \times 100
\end{aligned}
$$

\section{QOL questionnaire}

QOL and health status were measured using the validated, self-administered, generic Short Form-36 (SF36) health survey, which consists of 36 questions within 8 scales to assess health and functional status: physical function (PF), role limitation-physical (RP), bodily pain (BP), general health (GH), vitality (VT), social function (SF), role limitation-emotion (RE), and mental health (MH) $[23,24]$. The response to each question is rated from 0 (worst) to 100 (best), with higher scores indicating a better health status. The SF-36 has been previously and successfully used for patients with lymphedema [4,5,16,17,25-27]. In the present study, the Korean version of the SF-36 was constructed for self-administration with each enrolled patient before each volume measurement [24].

\section{Satisfaction questionnaire}

After the CDT, a self-reported, study-specific survey re- garding the effectiveness of and satisfaction with the CDT was conducted. It consisted of 4 questions based on a 6 -point Likert scale (0, extremely dissatisfied; 1 , very dissatisfied; 2 , somewhat dissatisfied; 3 , somewhat satisfied; 4, very satisfied; and 5, extremely satisfied) (Appendix A). The questionnaire also included demographic items and questions associated with the details of the lymphedema. When requested, a trained physical therapist assisted the patients with the questionnaire.

\section{Statistical analysis}

The baseline demographic profiles were compared between two conditions in two groups (AL and LL, and LL and primary leg lymphedema [PL]) using independent ttests. The primary outcomes of SF-36 score and reduction in PCEV were compared from baseline to 2 weeks and 14 weeks using repeated measured ANOVAs, independent ttests and paired t-tests. These analyses were conducted with limbs or causes as the primary factor, and time (pre-CDT, post-CDT, and 12 weeks after post-CDT) as the nested factor. Independent t-tests were performed to determine the difference in self-reported satisfaction between the two conditions in two groups (AL and LL, PL and LL). Pearson correlation analyses were conducted to determine associations between the reduction in PCEV and pre-CDT PCEV. All the collected data were analyzed using SPSS ver, 20.0 (IBM Corp., Armonk, NY, USA).

\section{RESULTS}

\section{Clinical characteristics}

The patient characteristics are presented in Table 1. AL was present in 35 patients, and the remaining 49 patients had lower extremity lymphedema (LL and PL). With AL,

Table 1. Characteristics of patients with lymphedema

\begin{tabular}{lcccc}
\hline & $\begin{array}{c}\text { Arm lymphedema } \\
(\mathbf{n = 3 5})\end{array}$ & $\begin{array}{c}\text { Leg lymphedema } \\
(\mathbf{n = 3 5 )}\end{array}$ & $\begin{array}{c}\text { Primary lymphedema } \\
(\mathbf{n = 1 4 )}\end{array}$ & p-value \\
\hline Age (yr) & $45.57 \pm 9.28$ & $58.00 \pm 8.47$ & $41.86 \pm 12.56$ & 0.62 \\
\hline Women & $35(100)$ & $29(82.86)$ & $11(78.57)$ & 0.09 \\
Right side affected & $15(42.86)$ & $16(45.71)$ & $7(50.00)$ & 0.82 \\
Height $(\mathrm{cm})$ & $160.60 \pm 5.52$ & $158.09 \pm 7.69$ & $162.71 \pm 7.62$ & 0.62 \\
Weight $(\mathrm{kg})$ & $58.80 \pm 10.06$ & $63.28 \pm 10.23$ & $62.86 \pm 15.26$ & 0.48 \\
PCEV (\%) & $20.90 \pm 15.49$ & $23.57 \pm 11.27$ & $24.75 \pm 13.27$ & 0.25 \\
\hline
\end{tabular}

Values are presented as mean \pm standard deviation or number (\%).

PCEV, percent excess volume. 
only secondary lymphedema was present, and all patients had received prior treatment for breast cancer. Of the lower extremity patients, 14 had PL and 35 had LL. Of the LL patients, 19 (54\%) patients had gynecologic cancer, $6(17 \%)$ had prostate cancer, 5 (14\%) had lymphoma, and 5 (14\%) had other types of cancers. There were no differences in demographic characteristics among the $\mathrm{AL}, \mathrm{LL}$, and PL groups, except for a higher proportion of men in the lower extremity lymphedema (LL and PL) patients.

\section{Volume}

Mean baseline PCEV was $20.92 \%$ in AL, $23.57 \%$ in LL, and $24.75 \%$ in PL, relative to the normal limbs, and PCEV decreased post-CDT by $4.54 \%$ (21.69\% of the pre-CDT PCEV; $p=0.001$ ), $5.61 \%$ ( $23.78 \%$ of the pre-CDT PCEV; $\mathrm{p}=0.001)$, and $6.00 \%$ (24.22\% of the pre-CDT PCEV; $\mathrm{p}=0.01$ ), respectively, compared with baseline (differ- ence, $\mathrm{F}=0.31, \mathrm{p}=0.73)$. At 12 weeks after treatment, the PCEV decreased by $5.66 \%$ (27.02\% of the pre-CDT PCEV) in AL patients, $6.07 \%$ (25.75\% of the pre-CDT PCEV) in LL patients, and $6.37 \%$ (25.74\% of the pre-CDT PCEV) in PL patients, compared with baseline (difference, $\mathrm{F}=0.15$, $\mathrm{p}=0.86$ ). The differences in the change in PCEV between the groups were not significant at both post-CDT and 12 weeks after CDT (Tables 2, 3).

Patterns of volume reductions when expressed as PCEV remaining were similar between the groups. The initial 2 weeks represented the majority of PCEV reduction (Tables $2,3)$. A statistically significant effect of time was evident from repeated measures analysis; however, this effect was restricted to the CDT sessions $(p<0.001)$. The effects of the treatment and interaction of time by limbs or type were not significant (by limbs, $\mathrm{p}=0.96$; by type, $\mathrm{p}=0.99$ ). Because of these overall non-significant results for the

Table 2. Changes in limb volume (\%) and quality of life, as measured by the Short Form-36, at three time points before and after complex decongestive therapy by lymphedema type (PL and LL)

\begin{tabular}{|c|c|c|c|c|c|c|}
\hline & Pre-CDT & Post-CDT & $\begin{array}{l}12 \text { weeks after } \\
\text { post-CDT }\end{array}$ & \multicolumn{2}{|c|}{ p-value } & $\mathbf{F}$ \\
\hline PL & $24.75 \pm 13.27$ & $18.75 \pm 12.91$ & $18.38 \pm 11.78$ & $0.01^{* b)}$ & $0.97^{\mathrm{c})}$ & 0.02 \\
\hline LL & $23.57 \pm 11.38$ & $17.97 \pm 10.44$ & $17.50 \pm 10.15$ & $<0.001^{* * * b)}$ & & \\
\hline p-value & $0.76^{\text {a) }}$ & $0.82^{\text {a) }}$ & $0.80^{\mathrm{a})}$ & & & \\
\hline \multicolumn{7}{|c|}{ Physical function } \\
\hline PL & $71.43 \pm 13.22$ & $78.21 \pm 18.36$ & $80.36 \pm 8.43$ & $0.13^{* b)}$ & $0.64^{\mathrm{c})}$ & 0.45 \\
\hline LL & $58.86 \pm 22.03$ & $67.57 \pm 19.79$ & $73.43 \pm 21.55$ & $<0.001^{* * * b)}$ & & \\
\hline $\mathrm{p}$-value & $0.05^{\mathrm{a})}$ & $0.09^{\text {a) }}$ & $0.11^{\mathrm{a})}$ & & & \\
\hline \multicolumn{7}{|c|}{ Role-physical } \\
\hline PL & $30.36 \pm 34.22$ & $37.50 \pm 21.37$ & $55.00 \pm 28.15$ & $0.06^{\mathrm{b})}$ & $0.84^{\mathrm{c})}$ & 0.18 \\
\hline LL & $23.57 \pm 34.27$ & $29.29 \pm 34.56$ & $41.43 \pm 40.19$ & $0.02^{* b)}$ & & \\
\hline p-value & $0.53^{\mathrm{a})}$ & $0.32^{\mathrm{a})}$ & $0.19^{\text {a) }}$ & & & \\
\hline \multicolumn{7}{|c|}{ Bodily pain } \\
\hline PL & $20.18 \pm 17.42$ & $78.39 \pm 25.77$ & $77.50 \pm 19.39$ & $<0.001^{* * * b)}$ & $0.94^{\mathrm{c})}$ & 0.07 \\
\hline LL & $52.57 \pm 24.22$ & $80.36 \pm 24.43$ & $77.29 \pm 24.71$ & $<0.001^{* * * b)}$ & & \\
\hline $\mathrm{p}$-value & $0.74^{\mathrm{a})}$ & $0.80^{\mathrm{a})}$ & $0.98^{\text {a) }}$ & & & \\
\hline \multicolumn{7}{|c|}{ General health } \\
\hline PL & $47.64 \pm 14.78$ & $57.50 \pm 13.55$ & $59.29 \pm 19.40$ & $0.03^{* b)}$ & $0.65^{\mathrm{c})}$ & 0.44 \\
\hline LL & $43.91 \pm 19.92$ & $57.43 \pm 18.88$ & $62.57 \pm 24.63$ & $<0.001^{* * * b)}$ & & \\
\hline p-value & $0.53^{\mathrm{a})}$ & $0.99^{\mathrm{a})}$ & $0.66^{\mathrm{a})}$ & & & \\
\hline \multicolumn{7}{|c|}{ Physical component summary } \\
\hline PL & $49.90 \pm 13.40$ & $62.90 \pm 13.86$ & $68.04 \pm 12.31$ & $<0.001^{* * * b)}$ & $0.98^{\mathrm{c})}$ & 0.02 \\
\hline LL & $44.73 \pm 19.26$ & $58.66 \pm 17.92$ & $63.68 \pm 22.69$ & $<0.001^{* * * b)}$ & & \\
\hline p-value & $0.36^{\text {a) }}$ & $0.43^{\text {a) }}$ & $0.39^{\text {a) }}$ & & & \\
\hline
\end{tabular}


Table 2. Continued

\begin{tabular}{|c|c|c|c|c|c|c|}
\hline & Pre-CDT & Post-CDT & $\begin{array}{l}12 \text { weeks after } \\
\text { post-CDT }\end{array}$ & \multicolumn{2}{|c|}{ p-value } & $\mathbf{F}$ \\
\hline PL & $43.71 \pm 18.59$ & $54.64 \pm 23.49$ & $63.93 \pm 14.17$ & $<0.001^{* * * b)}$ & $0.91^{\mathrm{c})}$ & 0.10 \\
\hline LL & $48.43 \pm 24.46$ & $61.86 \pm 20.83$ & $68.64 \pm 16.19$ & $<0.001^{* * * b)}$ & & \\
\hline p-value & $0.52^{\text {a) }}$ & $0.30^{\mathrm{a})}$ & $0.35^{\mathrm{a})}$ & & & \\
\hline \multicolumn{7}{|c|}{ Social function } \\
\hline PL & $55.36 \pm 15.28$ & $72.32 \pm 17.80$ & $82.14 \pm 16.05$ & $<0.001^{* * * b)}$ & $0.93^{\mathrm{c})}$ & 0.08 \\
\hline LL & $50.00 \pm 20.11$ & $65.36 \pm 27.80$ & $73.57 \pm 24.21$ & $<0.001^{* * * b)}$ & & \\
\hline p-value & $0.38^{\text {a) }}$ & $0.39^{\text {a) }}$ & $0.23^{\mathrm{a})}$ & & & \\
\hline \multicolumn{7}{|c|}{ Role-emotional } \\
\hline PL & $50.00 \pm 42.87$ & $53.57 \pm 44.42$ & $57.14 \pm 44.20$ & $0.90^{\mathrm{b})}$ & $0.24^{\mathrm{c})}$ & 1.447 \\
\hline LL & $38.09 \pm 42.12$ & $56.19 \pm 44.11$ & $71.43 \pm 38.89$ & $<0.001^{* * * b)}$ & & \\
\hline p-value & $0.38^{\text {a) }}$ & $0.85^{\text {a) }}$ & $0.27^{\mathrm{a})}$ & & & \\
\hline \multicolumn{7}{|c|}{ Mental health } \\
\hline PL & $63.43 \pm 19.33$ & $74.21 \pm 16.87$ & $70.00 \pm 14.36$ & $0.13^{\mathrm{b})}$ & $0.32^{\mathrm{c})}$ & 1.16 \\
\hline LL & $57.60 \pm 21.13$ & $73.03 \pm 21.35$ & $73.37 \pm 23.62$ & $<0.001^{* * * b)}$ & & \\
\hline p-value & $0.38^{\text {a) }}$ & $0.85^{\mathrm{a})}$ & $0.55^{\mathrm{a})}$ & & & \\
\hline \multicolumn{7}{|c|}{ Mental component summary } \\
\hline PL & $53.12 \pm 18.60$ & $63.69 \pm 20.14$ & $68.30 \pm 14.56$ & $0.04^{* \mathrm{~b})}$ & $0.46^{\mathrm{c})}$ & 0.78 \\
\hline LL & $48.53 \pm 19.09$ & $64.11 \pm 21.52$ & $71.75 \pm 21.66$ & $<0.001^{* * * b)}$ & & \\
\hline p-value & $0.45^{\text {a) }}$ & $0.95^{\text {a) }}$ & $0.52^{\text {a) }}$ & & & \\
\hline
\end{tabular}

Values are presented as mean \pm standard deviation.

CDT, complex decongestive therapy; PCEV, percent excess volume; PL, primary leg lymphedema; LL, secondary leg lymphedema.

${ }^{*} \mathrm{p}<0.05,{ }^{* *} \mathrm{p}<0.01,{ }^{* * *} \mathrm{p}<0.001$.

a) $p$-values were derived from independent $t$-tests, ${ }^{\text {b) }} \mathrm{p}$-values were derived from repeated measured ANOVAs for the effect of time as the within subject factor (3 levels: pre-CDT, post-CDT, and 12 weeks after post-CDT), ${ }^{c}$ p-values were derived from repeated measured ANOVAs for the effect of time as the between subjects factor (2 levels: PL and LL).

Table 3. Changes in limb volume (\%) and quality of life, as measured by the Short Form-36, at three time points before and after complex decongestive therapy by limb (AL and LL)

\begin{tabular}{|c|c|c|c|c|c|c|}
\hline & Pre-CDT & Post-CDT & $\begin{array}{l}12 \text { weeks after } \\
\text { post-CDT }\end{array}$ & \multicolumn{2}{|c|}{ p-value } & $\mathbf{F}$ \\
\hline $\mathrm{AL}$ & $20.93 \pm 10.22$ & $16.39 \pm 8.07$ & $15.27 \pm 9.09$ & $<0.001^{* * * \mathrm{~b})}$ & $0.81^{\mathrm{c})}$ & 0.22 \\
\hline LL & $23.57 \pm 11.38$ & $17.97 \pm 10.44$ & $17.50 \pm 10.15$ & $<0.001^{* * * b)}$ & & \\
\hline $\mathrm{p}$-value & $0.31^{\mathrm{a})}$ & $0.48^{\mathrm{a})}$ & $0.34^{\mathrm{a})}$ & & & \\
\hline \multicolumn{7}{|c|}{ Physical function } \\
\hline $\mathrm{AL}$ & $74.86 \pm 13.42$ & $74.14 \pm 14.58$ & $80.00 \pm 10.07$ & $0.01^{* \mathrm{~b})}$ & $0.02^{* c)}$ & 3.96 \\
\hline LL & $58.86 \pm 22.03$ & $67.57 \pm 19.79$ & $73.43 \pm 21.55$ & $<0.001^{* * * b)}$ & & \\
\hline $\mathrm{p}$-value & $0.001^{* * a)}$ & $0.12^{\mathrm{a})}$ & $0.11^{\text {a) }}$ & & & \\
\hline \multicolumn{7}{|c|}{ Role-physical } \\
\hline $\mathrm{AL}$ & $17.14 \pm 22.50$ & $22.14 \pm 30.18$ & $40.71 \pm 35.40$ & $<0.001^{* * * b)}$ & $0.72^{\mathrm{c})}$ & 0.34 \\
\hline LL & $23.57 \pm 34.27$ & $29.29 \pm 34.56$ & $41.43 \pm 40.19$ & $0.02^{* \mathrm{~b})}$ & & \\
\hline $\mathrm{p}$-value & $0.36^{\text {a) }}$ & $0.36^{\text {a) }}$ & $0.94^{\mathrm{a})}$ & & & \\
\hline
\end{tabular}


Table 3. Contined

\begin{tabular}{|c|c|c|c|c|c|c|}
\hline & Pre-CDT & Post-CDT & $\begin{array}{l}12 \text { weeks after } \\
\text { post-CDT }\end{array}$ & \multicolumn{2}{|c|}{ p-value } & $\mathbf{F}$ \\
\hline $\mathrm{AL}$ & $66.56 \pm 25.76$ & $79.71 \pm 20.36$ & $82.79 \pm 18.99$ & $0.001^{* * \mathrm{~b})}$ & $0.05^{\mathrm{c})}$ & 3.03 \\
\hline LL & $52.57 \pm 24.22$ & $80.36 \pm 24.43$ & $77.29 \pm 24.71$ & $<0.001^{* * * \mathrm{~b})}$ & & \\
\hline p-value & $0.02^{* a)}$ & $0.91^{\mathrm{a})}$ & $0.30^{\mathrm{a})}$ & & & \\
\hline \multicolumn{7}{|c|}{ General health } \\
\hline $\mathrm{AL}$ & $59.29 \pm 19.86$ & $59.91 \pm 19.63$ & $63.14 \pm 19.48$ & $0.25^{\mathrm{b})}$ & $0.005^{* * c)}$ & 5.86 \\
\hline LL & $43.91 \pm 19.92$ & $57.43 \pm 18.88$ & $62.57 \pm 24.63$ & $<0.001^{* * * \mathrm{~b})}$ & & \\
\hline $\mathrm{p}$-value & $0.002^{* * a)}$ & $0.59^{\text {a) }}$ & $0.92^{\text {a) }}$ & & & \\
\hline \multicolumn{7}{|c|}{ Physical component summary } \\
\hline $\mathrm{AL}$ & $54.46 \pm 14.17$ & $58.97 \pm 14.09$ & $66.66 \pm 14.87$ & $<0.001^{* * * \mathrm{~b})}$ & $0.04^{* c)}$ & 3.43 \\
\hline LL & $44.73 \pm 19.26$ & $58.66 \pm 17.92$ & $63.68 \pm 22.69$ & $<0.001^{* * * \mathrm{~b})}$ & & \\
\hline $\mathrm{p}$-value & $0.02^{* a)}$ & $0.94^{\mathrm{a})}$ & $0.52^{\mathrm{a})}$ & & & \\
\hline \multicolumn{7}{|l|}{ Vitality } \\
\hline AL & $59.57 \pm 20.84$ & $60.29 \pm 22.52$ & $65.14 \pm 19.98$ & $0.10^{\mathrm{b})}$ & $0.007^{* * c)}$ & 5.41 \\
\hline LL & $48.43 \pm 24.46$ & $61.86 \pm 20.83$ & $68.64 \pm 16.19$ & $<0.001^{* * * \mathrm{~b})}$ & & \\
\hline p-value & $0.04^{* a)}$ & $0.76^{\text {a) }}$ & $0.42^{\mathrm{a})}$ & & & \\
\hline \multicolumn{7}{|c|}{ Social function } \\
\hline $\mathrm{AL}$ & $63.43 \pm 22.77$ & $64.64 \pm 20.00$ & $76.57 \pm 19.88$ & $0.003^{* * \mathrm{~b})}$ & $0.07^{\mathrm{c})}$ & 2.74 \\
\hline LL & $50.00 \pm 20.11$ & $65.36 \pm 27.80$ & $73.57 \pm 24.21$ & $<0.001^{* * * \mathrm{~b})}$ & & \\
\hline $\mathrm{p}$-value & $0.01^{* a)}$ & $0.90^{\mathrm{a})}$ & $0.57^{\mathrm{a})}$ & & & \\
\hline \multicolumn{7}{|c|}{ Role-emotional } \\
\hline AL & $41.90 \pm 45.26$ & $58.09 \pm 41.50$ & $59.05 \pm 38.38$ & $0.03^{* \mathrm{~b})}$ & $0.23^{\mathrm{c})}$ & 1.48 \\
\hline LL & $38.09 \pm 42.12$ & $56.19 \pm 44.11$ & $71.43 \pm 38.89$ & $<0.001^{* * * \mathrm{~b})}$ & & \\
\hline $\mathrm{p}$-value & $0.71^{\text {a) }}$ & $0.85^{\mathrm{a})}$ & $0.16^{\text {a) }}$ & & & \\
\hline \multicolumn{7}{|c|}{ Mental health } \\
\hline $\mathrm{AL}$ & $67.20 \pm 17.86$ & $71.77 \pm 18.86$ & $75.77 \pm 18.48$ & $0.02^{* \mathrm{~b})}$ & $0.04^{* c)}$ & 3.29 \\
\hline LL & $57.60 \pm 21.13$ & $73.03 \pm 21.35$ & $73.37 \pm 23.62$ & $<0.001^{* * * b)}$ & & \\
\hline p-value & $0.04^{* a)}$ & $0.80^{\mathrm{a})}$ & $0.64^{\mathrm{a})}$ & & & \\
\hline \multicolumn{7}{|c|}{ Mental component summary } \\
\hline $\mathrm{AL}$ & $58.03 \pm 20.48$ & $63.70 \pm 19.19$ & $69.13 \pm 16.06$ & $0.01^{* b)}$ & $0.02^{c)}$ & 4.20 \\
\hline LL & $48.53 \pm 19.09$ & $64.11 \pm 21.52$ & $71.75 \pm 21.66$ & $<0.001^{* * * \mathrm{~b})}$ & & \\
\hline p-value & $0.05^{\mathrm{a})}$ & $0.93^{\mathrm{a})}$ & $0.57^{\mathrm{a})}$ & & & \\
\hline
\end{tabular}

Values are presented as mean \pm standard deviation.

CDT, complex decongestive therapy; PCEV, percent excess volume; AL, arm lymphedema; LL, leg lymphedema.

${ }^{*} \mathrm{p}<0.05,{ }^{* *} \mathrm{p}<0.01,{ }^{* * *} \mathrm{p}<0.001$.

a) $\mathrm{p}$-values were derived from independent $\mathrm{t}$-tests, ${ }^{\text {b) }} \mathrm{p}$-values were derived from repeated measured ANOVAs for the effect of time as the within subject factor (3 levels: pre-CDT, post-CDT, and 12 weeks after post-CDT), ${ }^{c}$ p-values were derived from repeated measured ANOVAs for the effect of time as the between subjects factor (2 levels: AL and LL).

primary outcome, subgroup analyses were not conducted.

The Pearson correlation analyses resulted in significant correlations between the reduction in PCEV (pre-CDT to
post-CDT, and pre-CDT to 12 weeks after post-CDT) and pre-CDT PCEV ( $r=0.48, \mathrm{p}<0.001 ; \mathrm{r}=0.49, \mathrm{p}<0.001$, respectively). 


\section{Quality of life}

In all groups, SF-36 scores were significantly lower than that of the Korean population means in almost all domains $[24,28]$. There were no significant differences in the SF-36 scores for any of the time points between the PL and LL patients ( $p=0.69)$, but there were significant differences in the mean pre-CDT SF-36 scores between the AL and LL patients ( $p=0.01)$. The subjects reported a mean increase, from pre-CDT, of 10.23 points at postCDT and 16.42 points at 12 weeks after post-CDT. Patients with LL showed more improved SF-36 scores than patients with AL (Table 3, Fig. 2).

PF $(p=0.001)$, VT $(p=0.04), B P(p=0.02), S F(p=0.01)$, $\mathrm{MH}(\mathrm{p}=0.04)$, and $\mathrm{GH}(\mathrm{p}=0.002)$ scales were significantly lower in LL patients than in AL patients at pre-CDT. How-

(A)

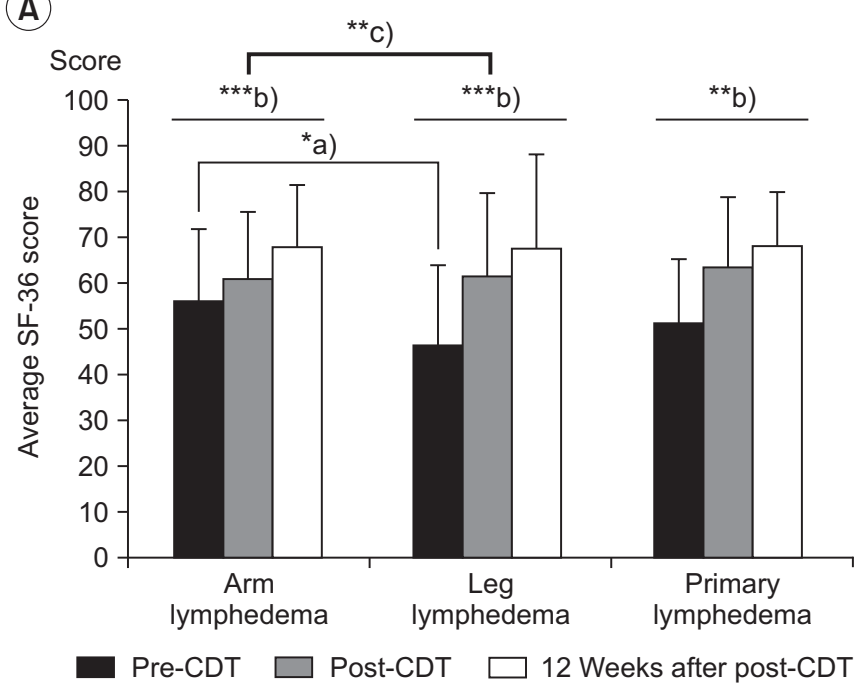

(C)

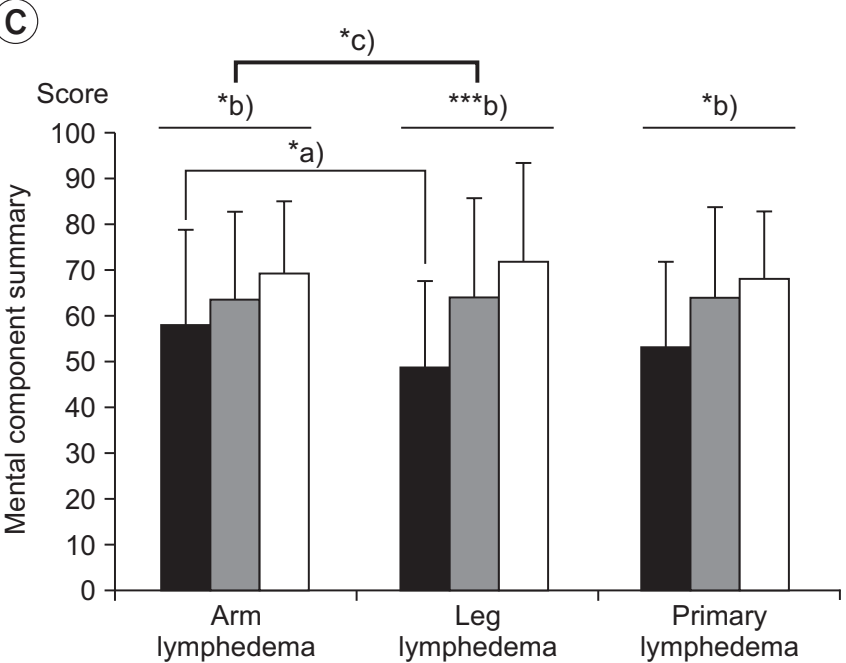

$\square$ Pre-CDT $\square$ Post-CDT $\square 12$ Weeks after post-CDT ever, no significant difference was noted in the 6 items at post-CDT and 12 weeks after post-CDT. At the end of the observation period, most measures had improved, and there were no significant differences between AL and LL.

In the repeated-measures ANOVAs that were conducted with time (pre-CDT, post-CDT, and 12 weeks after postCDT), a significant main effect for time between limb groups ( $\mathrm{AL}$ and $\mathrm{LL}$ ) was observed with the $\mathrm{PF}(\mathrm{F}=3.96$, $\mathrm{p}=0.02)$, GH ( $\mathrm{F}=5.86, \mathrm{p}=0.005)$, VT ( $\mathrm{F}=5.41, \mathrm{p}=0.007)$, and $\mathrm{MH}(\mathrm{F}=3.29, \mathrm{p}=0.04)$ scales.

\section{Satisfaction survey}

Satisfaction scores are reported in Fig. 3. The independent $\mathrm{t}$-test with equivalent variance showed no significant differences between the PL and LL groups. The self-

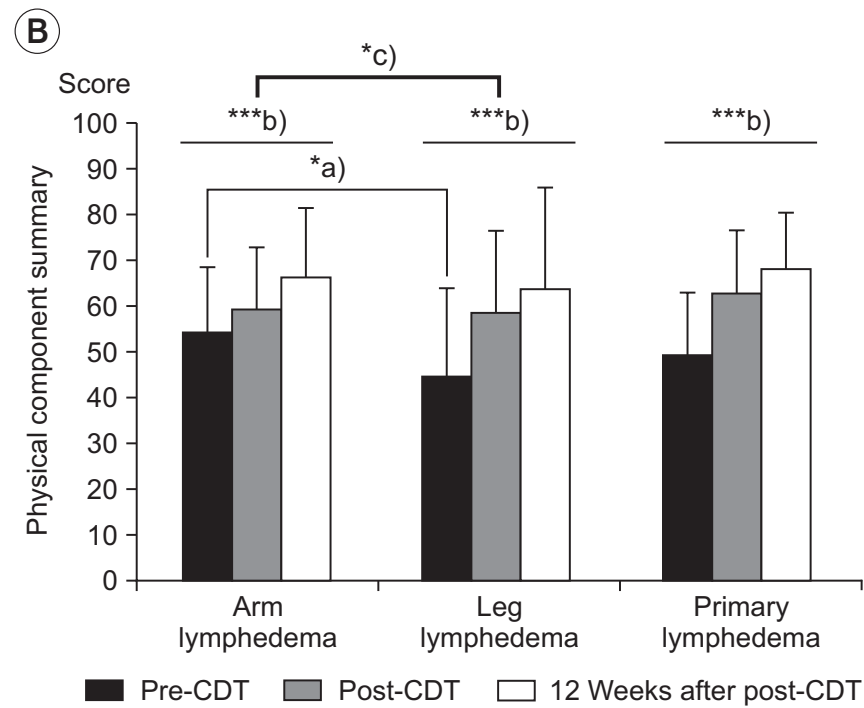

Fig. 2. Changes in quality of life, based on the Short Form-36, in patients with lymphedema who underwent complex decongestive therapy (CDT). (A) Average SF-36 score, (B) physical component summary, and (C) mental component summary. ${ }^{*} \mathrm{p}<0.05,{ }^{* *} \mathrm{p}<0.01,{ }^{* * *} \mathrm{p}<0.001,{ }^{\mathrm{a})} \mathrm{p}$ values were derived from independent $t$-tests, ${ }^{\text {b) }} \mathrm{p}$-values were derived from repeated measured ANOVAs for the effect of time for the within subject factor (3 levels: preCDT, post-CDT, and 12 weeks after post-CDT), ${ }^{c)}$-values were derived from repeated measured ANOVAs for the effect of time for the between subjects factor (2 levels: $\mathrm{AL}$ and LL, PL and LL). 
reported satisfaction scores from AL patients were lower than those from LL patients. Although no significant differences in volume reduction were observed between $\mathrm{AL}$ and LL, satisfaction was higher in LL patients.

\section{DISCUSSION}

Although several studies have focused on the overall deterioration in QOL over time, we are not aware of any previous study that has addressed differences in different limbs areas or lymphedema types. The current study evaluated the response of CDT characterized by 3 trajectories of type and limbs. Among 169 participants followed, 84 participants received efficacious CDT, and we tested the relationship between receiving CDT and the identified trajectories (AL, LL, and PL). The changing patterns of volume and QOL for all groups were examined for an identical period. Changes in all outcome measures were not significantly different between primary and secondary lymphedema. We found that the QOL of patients with LL was affected more than that of AL patients, and patients with LL experienced greater improvements in QOL and satisfaction with CDT.

The results of the present study are in close agreement with those of earlier studies that reported significant changes in edema volume and the mental and physical scales of the SF-36 over a 3-month period $[5,16,17,27]$. In all of the groups, the volume reduction primarily occurred within the 2 weeks of treatment, which is simi-

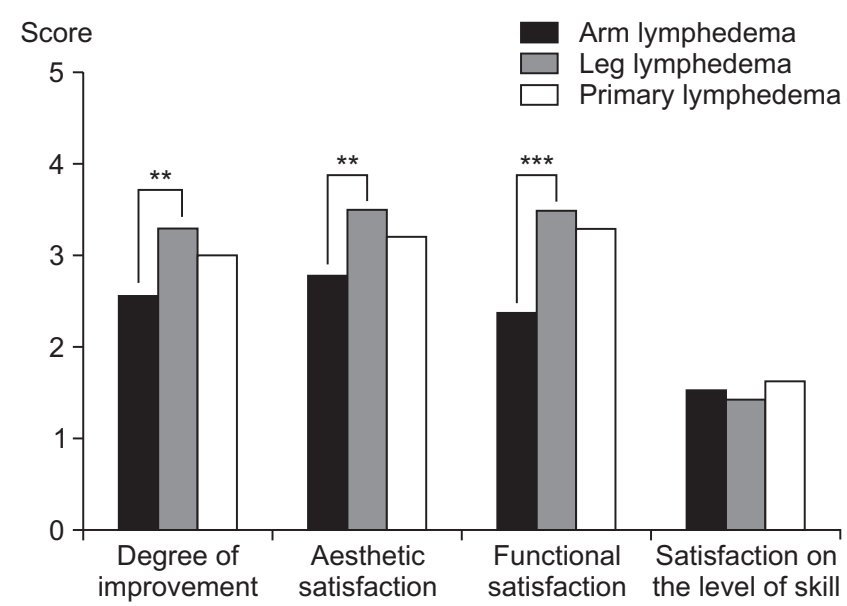

Fig. 3. Satisfaction with complex decongestive therapy in patients with lymphedema, based on the study-specific satisfaction survey. ${ }^{* *} \mathrm{p}<0.01,{ }^{* * *} \mathrm{p}<0.001, \mathrm{p}$-values were derived from independent t-tests. lar to previously reported findings $[4,5,18,26]$. Further lymphedema volume reductions that were evident at least 12 weeks after treatment were not statistically significant (Fig. 4).

The temporal improvement in edema volume was very similar in all groups, and a comparable magnitude of change occurred in all groups during the 14 weeks of the study. At 12 weeks after post-CDT, the edema volume had improved by $5.66 \%$ (27.02\% of the pre-CDT PCEV), $6.07 \%$ (25.75\% of the pre-CDT PCEV), and $6.37 \%$ (25.74\% of the pre-CDT PCEV) in the AL, LL, and PL groups, respectively. The results of the current study correspond well with those of an earlier study which reported that volume differences were similar in patients with either upper- or lower-extremity lymphedema [29].

A previous study found that the most important predictor of the volume reducing effect of CDT was the amount of swelling at the time of presentation [18,30,31]. Based on our experience, we expected that different reduction rates might be obtained based on the affected extremities and causes of lymphedema [32] and, similar to the aforementioned study, initial PCEV would affect CDT efficacy in both groups. However, there were no significant differences in the reduction rate of PCEV between the groups at any point during the trial. The current study showed that all groups produced similar changing patterns in PCEV, with CDT effectively promoting lymphedema volume reduction. This suggests that the affected limb or the

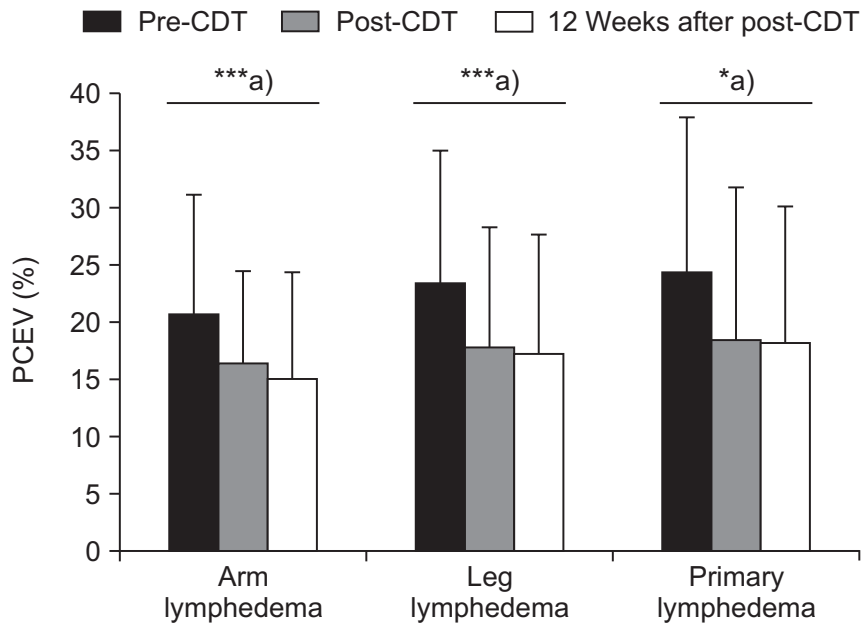

Fig. 4. Changes in limb volume in patients with lymphedema, based on complex decongestive therapy (CDT). PCEV, percent excess volume. ${ }^{* * *} \mathrm{p}<0.001,{ }^{\text {a) }} \mathrm{p}$-values were derived from paired t-tests. 
cause is not correlated with the volume reductive effects of CDT, and the initial excessive volume rate results in similar changes in PCEV in both groups.

There were differences in QOL between patients with lymphedema in different limbs at baseline (pre-CDT). In the observation period, which included the CDT period, almost all of the SF-36 items showed statistically significant improvement in both groups. In a similar study assessing QOL outcomes after CDT for cancer lymphedema, the investigators found that CDT improved overall QOL and was effective for various degrees of lymphedema $[4,5,12]$. Our analyses revealed the association of PCEV with SF-36. This association was markedly different in AL versus LL. Furthermore, CDT for LL resulted in greater treatment satisfaction. Because the clinical characteristics of AL such as cancer diagnosis, cancer treatment procedures and clinical courses may differ considerably from those of LL, we cannot generalize the results from the different effects of CDT. However our analyses revealed that differences in limbs might be predictive of changing patterns of QOL. Our findings suggest that the classification of types and limbs might be informative with regard to the aspect of QOL.

In our opinion, absolute PCEV may have a greater impact on QOL in patients with LL than in those with AL. However, it is not clear why lymphedema volume affects QOL more in those with LL than those with AL, although the impact on weight-bearing functions may provide an explanation. Volume reduction in the lower limb is essential for weight-bearing activities such as walking and transfer, which are included in SF-36 [16]. As such, these findings indicate early CDT is effective for lower-extremity lymphedema.

These results also can be useful in understanding the psychosocial impact of lymphedema. The observations of other studies show that significant psychosocial issues are associated with breast cancer related lymphedema more so than lymphedema from other causes $[33,34]$. In our opinion, great improvements in physical and emotional health could be achieved by recognizing the psychosocial needs of patients with upper-extremity lymphedema. It would be interesting as well to explore the reasons for such responsiveness via exploration of the two groups (AL and LL).

To the best of our knowledge, no studies have been conducted to assess satisfaction with CDT using self-report- ed data in CDT. The degree of improvement, aesthetic satisfaction, and functional satisfaction were significantly more improved with LL than AL. This might be related to the greater improvement in the SF-36 score. Thus, CDT for volume reduction therapy might be the best treatment for patients with LL.

There were other findings that may be of clinical relevance. In general, patients with lymphedema responded differently depending on the type of lymphedema. In contrast to what is generally known, it has been reported that was no statistical significance between the outcomes of primary and secondary lymphedema groups in all measures [10]. In the present study, even though lymphedema had different causes, the response to CDT was similar in many ways. Despite differences in cause, onset age, disease duration and clinical course, we suggest that the type of lymphedema does not fully reflect the etiology, and the common physiopathological mechanism of primary and secondary lymphedema has to be identified [35]. In general, the degree of edema is correlated with the amount of lymphatic reserves. It may unlatch with CDT and the diminution of the volume is obtained. Thus, the response is determined by the amount of lymphatic reserves and the provision of therapeutic benefits by CDT in both type of lymphedema. It is suggested that the type of lymphedema (primary or secondary) is not able to predict the outcomes or additionally inform the treatment plan.

Our study was limited by several important factors. Our sample cannot be considered fully representative of patients with lymphedema because we excluded patients with severe systemic diseases, bilateral lymphedema, and severe lymphedema. Therefore, it is difficult to generalize these results. Second, a direct comparison of the upper and lower limbs is challenging. Although SF-36 was not specifically designed to compare arm and leg function directly, the robustness of the results is demonstrated by comparable results across instruments [17,36-38]. Finally, the absence of a control group limits the ability to attribute changes to CDT in both groups. These limitations suggest possible directions for future study.

Despite these limitations, the different outcomes in AL and LL patients support the theory that CDT is more beneficial for LL than AL, including those for QOL and satisfaction. The findings indicate a need for different approaches in management and patient consultation 
approaches for upper- and lower-extremity lymphedema. Knowledge of potential factors that influence CDT outcomes would help clinicians develop care plans. Intensive treatment for patients with LL is essential for the reduction of excessive volumes. As a result of CDT, reduction in the volume of lymphedema in lower extremity lymphedema can lead to improvements in QOL $[5,30]$. However, simple volume reduction therapy does not improve treatment satisfaction in patients with AL [13]. Future studies are warranted to investigate the factors that are associated with QOL in AL patients, given that it is not completely dependent on volume. Future research is needed to determine the related factors and plan therapeutic strategies in order to achieve the optimal status for QOL.

In the long-term, over 14 weeks, CDT was found to be effective in lymphedema, but with different longitudinal courses in QOL improvement and satisfaction with treatment according to the limb and type. We found that the pattern of presentation changed with $\mathrm{CDT}$, with lower extremity lymphedema patients presenting more favorable outcomes in the aspects of QOL and satisfaction than upper extremity lymphedema patients. To sum up, clinicians should approach patients with different therapeutic considerations specific to each type or region of lymphedema. In patients with AL, simple volume reduction therapy does not improve satisfaction as well as QOL. Future clinical practice needs to detect LL early and address QOL through CDT. However, much more research remains to be done on the reasons for differences in responsiveness.

\section{CONFLICT OF INTEREST}

No potential conflict of interest relevant to this article was reported.

\section{REFERENCES}

1. Pusic AL, Cemal Y, Albornoz C, Klassen A, Cano S, Sulimanoff I, et al. Quality of life among breast cancer patients with lymphedema: a systematic review of patient-reported outcome instruments and outcomes. J Cancer Surviv 2013;7:83-92.

2. Cemal Y, Jewell S, Albornoz CR, Pusic A, Mehrara BJ. Systematic review of quality of life and patient report- ed outcomes in patients with oncologic related lower extremity lymphedema. Lymphat Res Biol 2013;11:14-9.

3. Deura I, Shimada M, Hirashita K, Sugimura M, Sato S, Sato $\mathrm{S}$, et al. Incidence and risk factors for lower limb lymphedema after gynecologic cancer surgery with initiation of periodic complex decongestive physiotherapy. Int J Clin Oncol 2014 Jul 4 [Epub]. http:// dx.doi.org/10.1007/s10147-014-0724-0.

4. Kim SJ, Yi CH, Kwon OY. Effect of complex decongestive therapy on edema and the quality of life in breast cancer patients with unilateral leymphedema. Lymphology 2007;40:143-51.

5. Kim SJ, Park YD. Effects of complex decongestive physiotherapy on the oedema and the quality of life of lower unilateral lymphoedema following treatment for gynecological cancer. Eur J Cancer Care (Engl) 2008;17:463-8.

6. Gurdal SO, Kostanoglu A, Cavdar I, Ozbas A, Cabioglu $\mathrm{N}$, Ozcinar B, et al. Comparison of intermittent pneumatic compression with manual lymphatic drainage for treatment of breast cancer-related lymphedema. Lymphat Res Biol 2012;10:129-35.

7. International Society of Lymphology. The diagnosis and treatment of peripheral lymphedema: 2013 Consensus Document of the International Society of Lymphology. Lymphology 2013;46):1-11.

8. Ryan M, Stainton MC, Jaconelli C, Watts S, MacKenzie $\mathrm{P}$, Mansberg T. The experience of lower limb lymphedema for women after treatment for gynecologic cancer. Oncol Nurs Forum 2003;30:417-23.

9. Badger C, Preston N, Seers K, Mortimer P. Physical therapies for reducing and controlling lymphoedema of the limbs. Cochrane Database Syst Rev 2004;(4):CD003141.

10. Demirtas Y, Ozturk N, Yapici O, Topalan M. Comparison of primary and secondary lower-extremity lymphedema treated with supermicrosurgical lymphaticovenous anastomosis and lymphaticovenous implantation. J Reconstr Microsurg 2010;26:137-43.

11. Hwang JH, Kwon JY, Lee KW, Choi JY, Kim BT, Lee $\mathrm{BB}$, et al. Changes in lymphatic function after complex physical therapy for lymphedema. Lymphology 1999;32:15-21.

12. Lasinski BB, McKillip Thrift K, Squire D, Austin MK, Smith KM, Wanchai A, et al. A systematic review of the evidence for complete decongestive therapy in the 
treatment of lymphedema from 2004 to 2011. PM R 2012;4:580-601.

13. Ridner SH. Quality of life and a symptom cluster associated with breast cancer treatment-related lymphedema. Support Care Cancer 2005;13:904-11.

14. Rowlands IJ, Beesley VL, Janda M, Hayes SC, Obermair A, Quinn MA, et al. Quality of life of women with lower limb swelling or lymphedema 3-5 years following endometrial cancer. Gynecol Oncol 2014;133:3148.

15. Sitzia J, Sobrido L. Measurement of health-related quality of life of patients receiving conservative treatment for limb lymphoedema using the Nottingham Health Profile. Qual Life Res 1997;6:373-84.

16. Franks PJ, Moffatt CJ, Doherty DC, Williams AF, Jeffs E, Mortimer PS. Assessment of health-related quality of life in patients with lymphedema of the lower limb. Wound Repair Regen 2006;14:110-8.

17. Hwang KH, Jeong HJ, Kim GC, Sim YJ. Clinical effectiveness of complex decongestive physiotherapy for malignant lymphedema: a pilot study. Ann Rehabil Med 2013;37:396-402.

18. Hwang JM, Hwang JH, Kim TW, Lee SY, Chang HJ, Chu IH. Long-term effects of complex decongestive therapy in breast cancer patients with arm lymphedema after axillary dissection. Ann Rehabil Med 2013; 37:690-7.

19. Adriaenssens N, Buyl R, Lievens P, Fontaine C, Lamote J. Comparative study between mobile infrared optoelectronic volumetry with a Perometer and two commonly used methods for the evaluation of arm volume in patients with breast cancer related lymphedema of the arm. Lymphology 2013;46:132-43.

20. Engelberger RP, Blazek C, Amsler F, Keo HH, Baumann F, Blattler W, et al. Reproducibility and day time bias correction of optoelectronic leg volumetry: a prospective cohort study. BMC Med Res Methodol 2011;11:138.

21. Sitzia J, Woods M, Hine P, Williams A, Eaton K, Green G. Characteristics of new referrals to twenty-seven lymphoedema treatment units. Eur J Cancer Care (Engl) 1998;7:255-62.

22. Forner-Cordero I, Munoz-Langa J, Forner-Cordero A, DeMiguel-Jimeno JM. Predictive factors of response to decongestive therapy in patients with breast-cancerrelated lymphedema. Ann Surg Oncol 2010;17:744-51.
23. Brazier JE, Harper R, Jones NM, O'Cathain A, Thomas KJ, Usherwood T, et al. Validating the SF-36 health survey questionnaire: new outcome measure for primary care. BMJ 1992;305:160-4.

24. Han CW, Lee EJ, Iwaya T, Kataoka H, Kohzuki M. Development of the Korean version of Short-Form 36Item Health Survey: health related QOL of healthy elderly people and elderly patients in Korea. Tohoku J Exp Med 2004;203:189-94.

25. Ahmed RL, Prizment A, Lazovich D, Schmitz KH, Folsom AR. Lymphedema and quality of life in breast cancer survivors: the Iowa Women's Health Study. J Clin Oncol 2008;26:5689-96.

26. Dayes IS, Whelan TJ, Julian JA, Parpia S, Pritchard KI, D'Souza DP, et al. Randomized trial of decongestive lymphatic therapy for the treatment of lymphedema in women with breast cancer. J Clin Oncol 2013;31:375863.

27. Pereira de Godoy JM, Braile DM, de Fatima Godoy M, Longo O Jr. Quality of life and peripheral lymphedema. Lymphology 2002;35:72-5.

28. Kim SH, Jo MW, Lee SI. Psychometric properties of the Korean short form-36 health survey version 2 for assessing the general population. Asian Nurs Res (Korean Soc Nurs Sci) 2013;7:61-6.

29. Szuba A, Cooke JP, Yousuf S, Rockson SG. Decongestive lymphatic therapy for patients with cancer-related or primary lymphedema. Am J Med 2000;109:296-300.

30. Liao SF, Li SH, Huang HY. The efficacy of complex decongestive physiotherapy (CDP) and predictive factors of response to CDP in lower limb lymphedema (LLL) after pelvic cancer treatment. Gynecol Oncol 2012;125:712-5.

31. Liao SF, Li SH, Huang HY, Chen ST, Kuo SJ, Chen DR, et al. The efficacy of complex decongestive physiotherapy (CDP) and predictive factors of lymphedema severity and response to CDP in breast cancer-related lymphedema (BCRL). Breast 2013;22:703-6.

32. Yamamoto R, Yamamoto T. Effectiveness of the treatment-phase of two-phase complex decongestive physiotherapy for the treatment of extremity lymphedema. Int J Clin Oncol 2007;12:463-8.

33. Ridner SH. The psycho-social impact of lymphedema. Lymphat Res Biol 2009;7:109-12.

34. Boccardo F, Campisi C. Disability and lymphedema. Ann Ital Chir 2002;73:485-8. 
35. Finegold DN, Schacht V, Kimak MA, Lawrence EC, Foeldi E, Karlsson JM, et al. HGF and MET mutations in primary and secondary lymphedema. Lymphat Res Biol 2008;6:65-8.

36. Davidson JH, Khor KE, Jones LE. A cross-sectional study of post-amputation pain in upper and lower limb amputees, experience of a tertiary referral amputee clinic. Disabil Rehabil 2010;32:1855-62.
37. Roh YH, Kim KW, Paik NJ, Kim TK, Gong HS. How much are upper or lower extremity disabilities associated with general health status in the elderly? Clin Orthop Relat Res 2012;470:3246-52.

38. Otero JE, Graves CM, TeKippe A, Buckwalter JA, Miller BJ. Factors affecting outcomes in patients treated surgically for upper extremity tumors and tumor-like lesions. Iowa Orthop J 2013;33:119-29. 
Appendix A. The study-specific satisfaction survey

A. Fill out demographic profile.

1. Demographics: Age, Height, Weight.

2. Underlying disease:

3. Lymphedema: onset, affected side.

B. Document your conditions.

\begin{tabular}{|c|c|c|c|c|c|c|}
\hline & $\begin{array}{l}\text { Extremely } \\
\text { dissatisfied }\end{array}$ & $\begin{array}{c}\text { Very } \\
\text { dissatisfied }\end{array}$ & $\begin{array}{l}\text { Somewhat } \\
\text { dissatisfied }\end{array}$ & $\begin{array}{c}\text { Somewhat } \\
\text { satisfied }\end{array}$ & $\begin{array}{c}\text { Very } \\
\text { satisfied }\end{array}$ & $\begin{array}{c}\text { Extremely } \\
\text { satisfied }\end{array}$ \\
\hline $\begin{array}{l}\text { Degree of improvement: } \\
\text { Were you satisfied with } \\
\text { this lymphedema treatment? }\end{array}$ & & & & & & \\
\hline $\begin{array}{l}\text { Functional satisfaction: } \\
\text { Do you feel that the affected limbs } \\
\text { have improved functionally after } \\
\text { lymphedema treatment? }\end{array}$ & & & & & & \\
\hline $\begin{array}{l}\text { Aesthetic satisfaction: } \\
\text { Do you think that the affected limbs } \\
\text { have improved cosmetically after } \\
\text { lymphedema treatment? }\end{array}$ & & & & & & \\
\hline
\end{tabular}

